\title{
Cyclic mechanical loading of unsaturated silty clay soils
}

\author{
Henok Hailemariam ${ }^{1, *}$, and Frank Wuttke ${ }^{1}$ \\ ${ }^{1}$ Geomechanics and Geotechnics, Kiel University, Ludewig-Meyn-Straße 10, 24118 Kiel, Germany
}

\begin{abstract}
Cyclic mechanical loading of soils due to natural causes such as earthquakes or due to loads coming from structures causes the accumulation of strains and excess pore-water pressures endangering the long term serviceability and stability of the structures built on them. In this study, un-drained cyclic loading tests at $0.1 \mathrm{~Hz}$ frequency are carried out on a normally consolidated unsaturated silty clay soil at different deviatoric stresses for up to around 1400 cycles. The results of the tests, which were performed using a recently developed cyclic electromechanical tri-axial device, show a significant dependence of the cyclic mechanical behavior of the silty clay soil, such as in the form of cyclic axial and accumulated plastic strains, on the number of cycles and applied deviatoric stresses.
\end{abstract}

\section{Introduction}

Cyclic mechanical loading of soils leads to the accumulation of plastic or permanent strains and development of excess pore-water pressures, compromising the safety and stability of structures built on them [1].

Cyclic loading behavior and the accumulation of high plastic strains of soils is also of importance in many practical cases of geotechnical engineering, where the tolerance to displacement is small, and may endanger the long term serviceability of the structures, ultimately causing serviceability failures, and hence should be carefully studied prior to the design and operation of the structures.

In this paper, the cyclic mechanical behavior of an unsaturated silty clay soil from Germany is assessed experimentally at different deviatoric stresses using a cyclic tri-axial device.

\section{Experimental program}

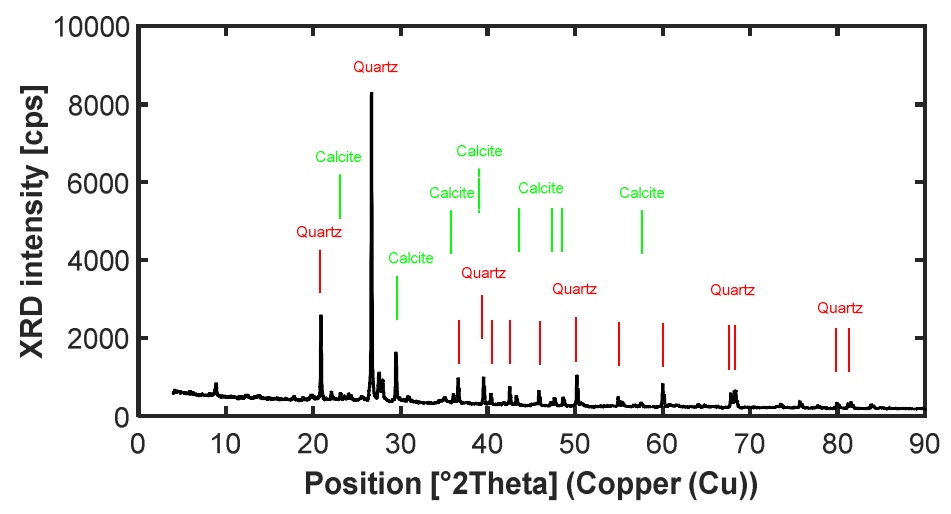

Fig. 2. XRD plot of the silty clay soil.

\footnotetext{
Corresponding author: henok.hailemariam@ifg.uni-kiel.de
} 


\subsection{Equipments used}

The cyclic mechanical behavior of the silty clay soil was analyzed experimentally using a recently developed electromechanical cyclic tri-axial testing device (Fig. 3).

The cyclic testing apparatus consists of a loading machine (with a capacity of $25 \mathrm{kN}$ and capable of applying cyclic deviatoric stresses with frequencies of up to $5 \mathrm{~Hz}$ ) for applying vertical deviatoric stresses, a dynamic high precision cell pressure system capable of applying cyclic cell pressure to the specimen, two WDC dynamic real time digital closed-loop actuator controllers, one for the deviatoric stress and the other for the cell pressure, a single volume-pressure-controller or VPC 10/1000 back-pressure application system, an optional (unused) Huber Ministat 125 Pilot ONE heat pump for controlling the temperature of the cell using a circulating fluid (glycol + distilled water), and a PC data logger system for control and data recording.

\subsection{Experimental procedure}

The cyclic tests were performed with a cell pressure of $100 \mathrm{kPa}$ and deviatoric stresses $\sigma_{d e v}$ of 40,60 and $80 \mathrm{kPa}$ were selected to be the base loads $\sigma_{d e v, b a s e}$ for the tests, which were conducted under unsaturated (natural moisture content) and fully drained conditions without the application of back-pressure.

The soil for testing was prepared at remolded natural gravimetric moisture condition, with a diameter of 50 $\mathrm{mm}$ and a height of $100 \mathrm{~mm}$ making sure that the top and bottom faces were perfectly flat to ensure uniform distribution of the deviatoric stresses. The cyclic loading tests were conducted at a frequency of $0.1 \mathrm{~Hz}$ with a deviatoric stress amplitude $\sigma_{d e v, a m p}$ of $15 \mathrm{kPa}$ for a number of cycles $N$ of up to a maximum of around 1400 .

Prior to the start of the cyclic tests, a sufficient consolidation time of around 24 hours was allotted for each cyclic test. The cyclic loading and displacement data was recorded at an acquisition rate of around 0.25 seconds. The mechanical loading (static and cyclic) schemes are schematically shown in Fig. 4. The static phase of loading of the soil was performed at a stress controlled rate of $2 \mathrm{kPa} / \mathrm{min}$.

Table 1. Physical properties of the silty clay soil.

\begin{tabular}{|c|c|}
\hline Property & Value \\
\hline Gravel, $>2 \mathrm{~mm}$ (wt.\%) & 16.1 \\
\hline Sand, 0.063 - 2 mm (wt.\%) & 8.8 \\
\hline Silt, 0.002 - 0.063 mm (wt.\%) & 58.2 \\
\hline Clay, <0.002 mm (wt.\%) & 16.8 \\
\hline Bulk dry density (kg m ${ }^{-3}$ ) & 1489 \\
\hline Porosity (-) & 0.443 \\
\hline Specific gravity of solids (-) & 2.673 \\
\hline Natural gravimetric water content (\%) & 16.8 \\
\hline Liquid limit (\%) & 34.6 \\
\hline Plasticity index (\%) & 14.81 \\
\hline Unified soil classification system (USCS) & $\mathrm{CL}^{(1)}$ \\
\hline (1) clay with low plasticity &
\end{tabular}

\section{Results and discussion}

\subsection{Time plots}

Figure 5 shows the time plot for the first three cycles of the cyclic loading tests of the silty clay soil at $\sigma_{\text {dev,base }}=$ $40 \mathrm{kPa}$.

The plot shows a substantial increase in the measured cyclic axial strains $\varepsilon_{c y c}$ of the soil with increasing number of cycles $N$, as the stress-strain loops generated due to the application of the cyclic loads are not completely closed.

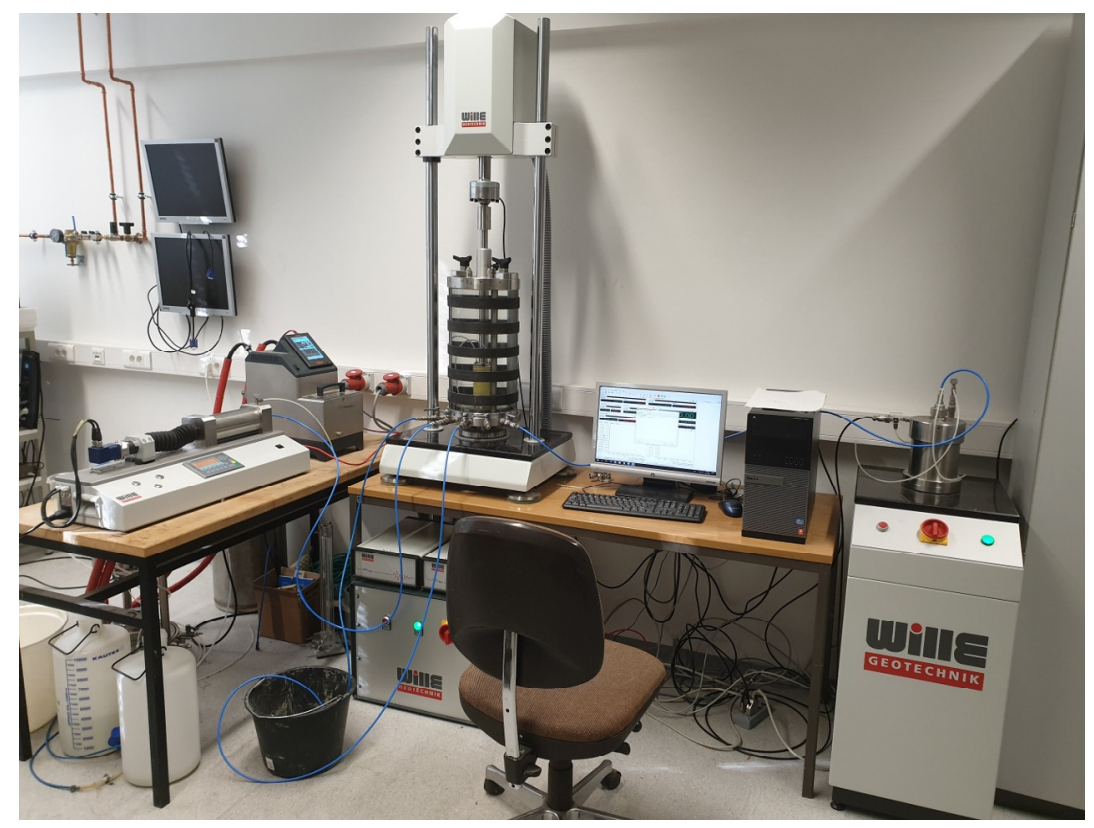

Fig. 3. Cyclic electromechanical tri-axial testing device used in the study.

\footnotetext{
Corresponding author: henok.hailemariam@ifg.uni-kiel.de
} 
For drained conditions, a cyclic loading can cause the accumulation of plastic strains at high number of cycles even for small amplitudes of loading causing differential settlements, and hence endangering the long-term serviceability of structures. For un-drained conditions, a cyclic loading with a considerably high amplitude (e.g. an earthquake) can cause the accumulation of high porewater pressures leading to the liquefaction or the loss of strength of the soil $[1,2,3]$.

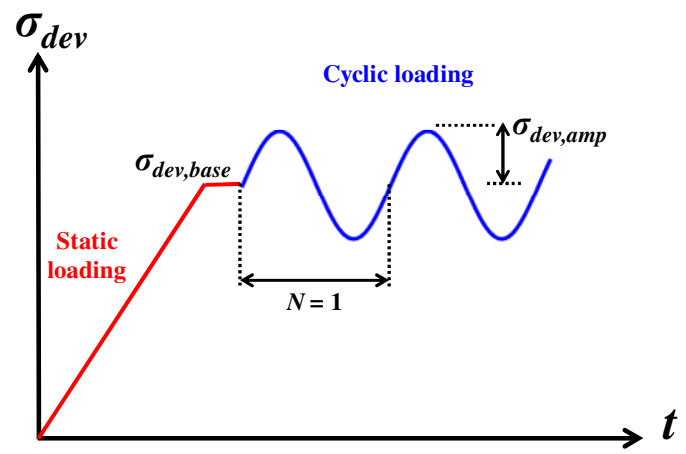

Fig. 4. Schematic representation of the mech. loading schemes.

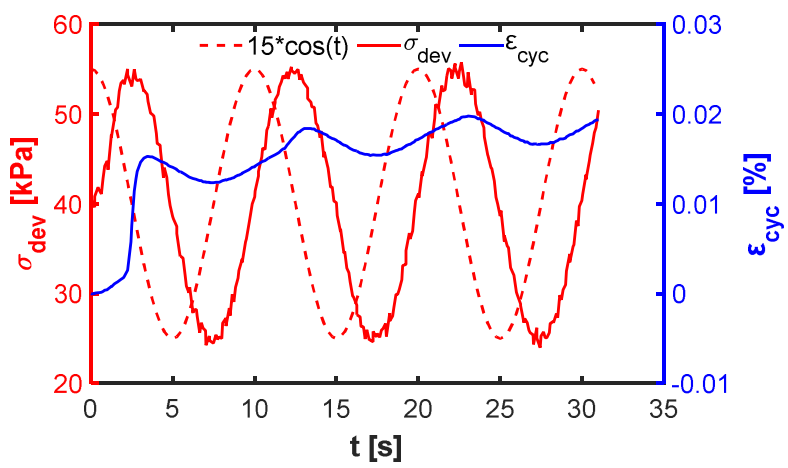

Fig. 5. Cyclic loading time plot of the silty clay soil with a deviatoric base stress $\sigma_{\text {dev,base }}$ of $40 \mathrm{kPa}$.

The increase in the measured $\varepsilon_{c y c}$ of the soil leads to irrecoverable strains and the accumulation of plastic strains $\varepsilon_{a c c}$ with each applied cycle. The cyclic frequency $f=0.1 \mathrm{~Hz}$ used in the study is in between 0 and $1 \mathrm{~Hz}$, hence, inertia forces are neglected and the accumulated deformations are largely considered to be plastic [4,5]. Furthermore, the magnitude of $\varepsilon_{a c c}$ of the soil is generally the highest during the first cycle, which is usually known as the irregular cycle (Fig. 5).

\subsection{Cyclic loading test results at different deviatoric base loads}

Figures 6 and 7 show the results of the cyclic loading tests which were conducted at room temperature with deviatoric base stresses $\sigma_{d e v, \text { base }}$ between 40 and $80 \mathrm{kPa}$.

The results show a considerable increase in the measured $\varepsilon_{c y c}$ (Fig. 6) and hence the accumulation of plastic strains $\varepsilon_{a c c}$ of the soil with increasing number of cycles $N$ at the studied deviatoric base loads. The measured magnitude of increase of the $\varepsilon_{a c c}$ of the soil is also directly proportional to the magnitudes of the applied deviatoric base loads $\sigma_{\text {dev,base }}$ (Fig. 7).
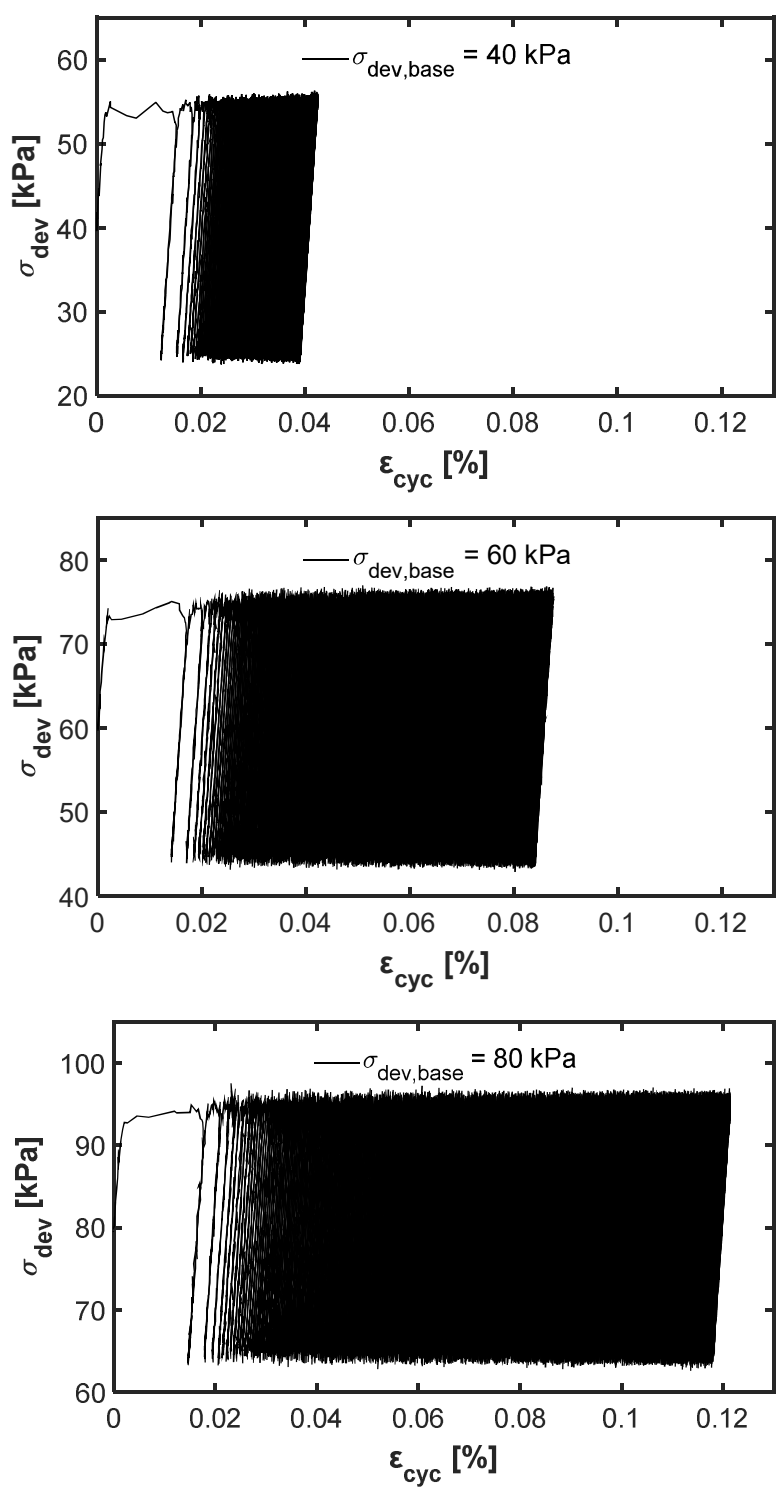

Fig. 6. Cyclic stress - strain plots of the soil at deviatoric base stresses of: $40 \mathrm{kPa}$ (top), $60 \mathrm{kPa}$ (middle) and $80 \mathrm{kPa}$ (bottom).

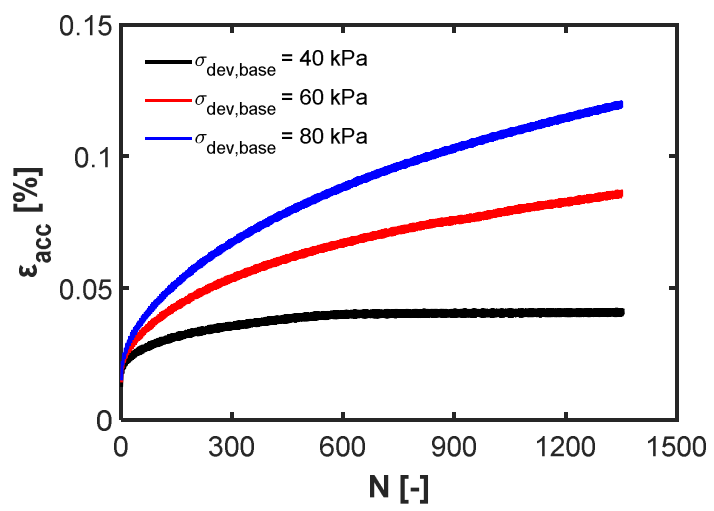

Fig. 7. Accumulated plastic strain vs. number of cycles of the silty clay soil at different deviatoric base stresses $\sigma_{d e v, \text { base }}$. 
Moreover, the rate of increase of the measured $\varepsilon_{a c c}$ of the soil is higher at the start of the cyclic tests and gradually slows down at higher number of cycles, indicating an increase of elasticity or elastic behavior of the quartz and calcite dominated soil skeleton.

When comparing the nature of the accumulation of plastic deformation of the soil due to cyclic loading with previous studies, at low deviatoric base stresse $\sigma_{\text {dev, base }}$, e.g. $40 \mathrm{kPa}$, it exhibits a shakedown behavior $[5,6]$ with most of the measured $\varepsilon_{a c c}$ occurring within the first circa 600 cycles and stabilizing afterwards (Fig. 7).

Whereas, for higher deviatoric base stresses $\sigma_{\text {dev, base, }}$ e.g. 60 and $80 \mathrm{kPa}$, the soil exhibits a form of incremental collapse, where the plastic strain increment decreases with increase in number of cycles without ever reaching a stable state and hence failure will occur eventually $[5,6]$.

\section{Conclusions}

Analyzing the mechanical behavior and the accurate estimation of the accumulated plastic strains of soils subjected to cyclic loading is vital in the design and long term serviceability of structures built upon them. In this research, the cyclic mechanical behavior of a silty clay soil from Germany was experimentally studied using a recently developed cyclic electromechanical tri-axial device. The findings showed a considerable increase in the measured axial cyclic and accumulated plastic strains of the soil with increasing number of cycles, and also a strong dependence on the applied deviatoric base stresses.

\section{Acknowledgements}

The authors gratefully acknowledge the financial support provided by the German Federal Ministry for Economic Affairs and Energy (BMWi) under the Grant number 03ET6122A (Project ANGUS II). We would also like to thank Brendan Ledwig of Kiel University for his support in analyzing the XRD measurements.

\section{References}

1. A. Sawicki, W. Swidzinski, International Journal for Numerical and Analytical Methods in Geomechanics 13 (1989)

2. O.C. Zienkiewicz, C.T. Chang, E. Hinton, International Journal for Numerical and Analytical Methods in Geomechanics 2 (1978)

3. W.D.L. Finn, Dynamic response analyses of saturated sands (In: Soil Mechanics-Transient and Cyclic Loads, Wiley, 1982)

4. P.K. Peralta, Investigations on the behavior of large diameter piles under long-term lateral cyclic loading in cohesionless soil. $\mathrm{PhD}$ thesis, Leibnitz Universität Hannover, Hannover, Germany (2010)

5. A. Shajarati, K.W. Sørensen, S.K. Nielsen, LB. Ibsen, Behaviour of cohesionless soils during cyclic loading. DCE Technical Memorandum, No. 14,
Department of Civil Engineering, Aalborg University, Aalborg, Denmark (2012)

6. M. Goldscheider, Shakedown and incremental collapse of structures in dry sand bodies (Proceedings of Dynamical Methods in Soil and Rock Mechanics, 2. Plastic and Long-Term Effects in Soils, Balkema, Rotterdam, Netherlands, 1978) 